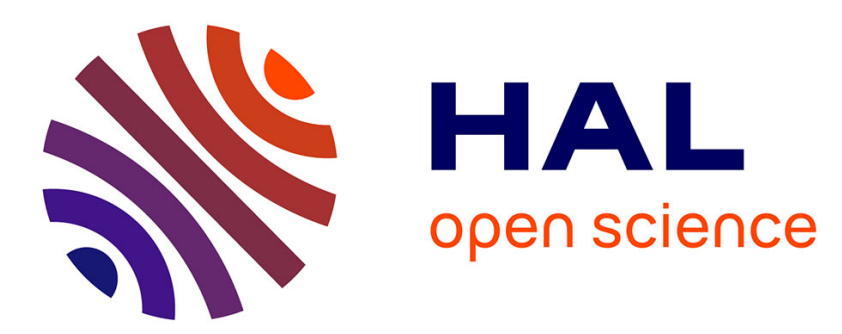

\title{
Interactions Between Tunnels and Unstable Slopes: Role of Excavation
}

\author{
Lionel Causse, Roger Cojean, Jean-Alain Fleurisson
}

\section{To cite this version:}

Lionel Causse, Roger Cojean, Jean-Alain Fleurisson. Interactions Between Tunnels and Unstable Slopes: Role of Excavation. XII IAEG Congrès, International Association for Engineering Geology and the Environment (IAEG), Sep 2014, Turin, Italy. pp.237 - 242, 10.1007/978-3-319-09057-3_34 . hal-01112269

\section{HAL Id: hal-01112269 \\ https://hal.science/hal-01112269}

Submitted on 2 Feb 2015

HAL is a multi-disciplinary open access archive for the deposit and dissemination of scientific research documents, whether they are published or not. The documents may come from teaching and research institutions in France or abroad, or from public or private research centers.
L'archive ouverte pluridisciplinaire HAL, est destinée au dépôt et à la diffusion de documents scientifiques de niveau recherche, publiés ou non, émanant des établissements d'enseignement et de recherche français ou étrangers, des laboratoires publics ou privés. 


\title{
Interactions between tunnels and unstable slopes - Role of excavation
}

\author{
Lionel CAUSSE $^{1}$, Roger COJEAN $^{1}$, Jean-Alain FLEURISSON ${ }^{1}$. \\ ${ }^{1}$ Mines ParisTech - Geosciences Research Department, 35 rue Saint Honoré, 77305, Fontainebleau, FRANCE.
}

\begin{abstract}
:
Back analysis of old tunnels in an unstable slope context leads to consider several situations of tunnel entering a slope: cross-cutting tunnel to slope, sloped tunnel, or shallow tunnel following the slope. Identified pathologies of structures vary depending on these situations. This research focuses on different slope mechanisms of instability, especially on creep processes and on damages affecting the structure of tunnels parallel to the slopes. The analysis of the Geotechnical Influenced Zone of these tunnel structures in slope context is a significant point of this study.

Through numerical simulations, the different aging and damage processes related to structures have been taken into account. Factors associated with geological and geomorphogical conditions of the slope along with their changes over time can be distinguished from factors corresponding to tunnel's excavations and construction methods. The influence of the first factors on the kinetics of movements and on the emergence of pathologies on structures can be revealed through the study of different geological, geomorphogical, hydrological and seismic contexts. This study focuses on the impact of building methods' parameters (excavation, reinforcement structures, supports and linings).

The excavation of a tunnel leads to a slope destabilization due to a more or less important deconfinement of the surrounding massif. Construction techniques influence, on one hand, slope destabilization with the development of shear strips and, on the other hand, structural damages in the tunnel lining. The relative influence of the deconfinement level when setting out the lining, the morphology of the transverse section of the tunnel, its dimensions and the characteristics of the lining structure are studied through several parametric studies.

As a conclusion, lessons are drawn about analysis methodologies of tunnel and the corresponding monitoring.
\end{abstract}

$\underline{\text { Key words: }}$ unstable slopes, tunnels, damages, numerical simulations, parametric studies, interaction tunnel-ground, Geotechnical Influenced Zone.

\section{INTRODUCTION}

The follow-up and the understanding of an unstable slope succeeds normally in a better understanding of mechanisms and process of activation of these as well as factors of intrinsic influence in the slope.

It's thus necessary to distinguish on one hand factors associated to those geologic and geomorphologic conditions of the slope and their evolutions simultaneously and on the other hand, factors corresponding to the method of excavation and construction of the tunnel.

Furthermore in the study of the interaction of a tunnel in a context of a instable slope, it's important to localize where does the tunnel is situated in the slope (relative orientation / height / height of the cover). First the relative orientation, that is to say, a transverse tunnel to the slope, turns with regard to this one or a shallow tunnel following the slope.

According to this first classification, various pathologies on the tunnel structure characterizing these situations were identified (Wang 2010).

However back-analyses of cases studies allowed specifying that these various characteristic pathologies, the structure can vary according to the orientation of the dynamics of theses instabilities in the slope compared to the axis of the tunnel.

The localization at high altitude of the tunnel in the slope influences this destabilization in a significant way: at the base of the slope the tunnel contributes to accelerate the movements within the slope compared with the case without any tunnel. Moreover, this situation at the base of the slope contributes to destabilize the slope more significantly than in another situation (center or head) of the tunnel in the slope (Koizumi et al. 2010).

The degree of interaction of a tunnel with instability of surface depends on the distance between the tunnel and the slope surface. The more the tunnel is closed to the weak surface the more the degree of interaction is important (Ashtiani et al. 2010). For a distance lower than 1.5 diameters of the tunnel, the interaction between a slip surface and a tunnel structure increases in an important way (Wang 2010).

This parametric study deals with various influence parameters relative to the destabilization of the slope associated with the construction methods (excavation, retaining structure and lining). 


\section{Numerical model}

\subsection{Model description}

Within the framework of this parametric study, the choice of the tunnel position near the base of the slope and at a distance of 1.5 diameters of the slope's surface is considered, according to the bibliographical study, as one of the most critical situation for the slope stability (Wang 2010). This study aim is to determine the influence of a tunnel excavation and more exactly:

- The effect of deconfinement before tunnel lining implementation;

- $\quad$ The size tunnel effect ;

- The shape tunnel effect.

The slope model chosen (Fig. 2.1), based on a principal plan is similar to the study (Koizumi et al. 2010), more exactly in a situation of a tunnel parallel to the slope, more or less close to the slope's surface. A finite difference method (FLAC 2D) has been used to simulate the interaction between tunnel and slope movement.

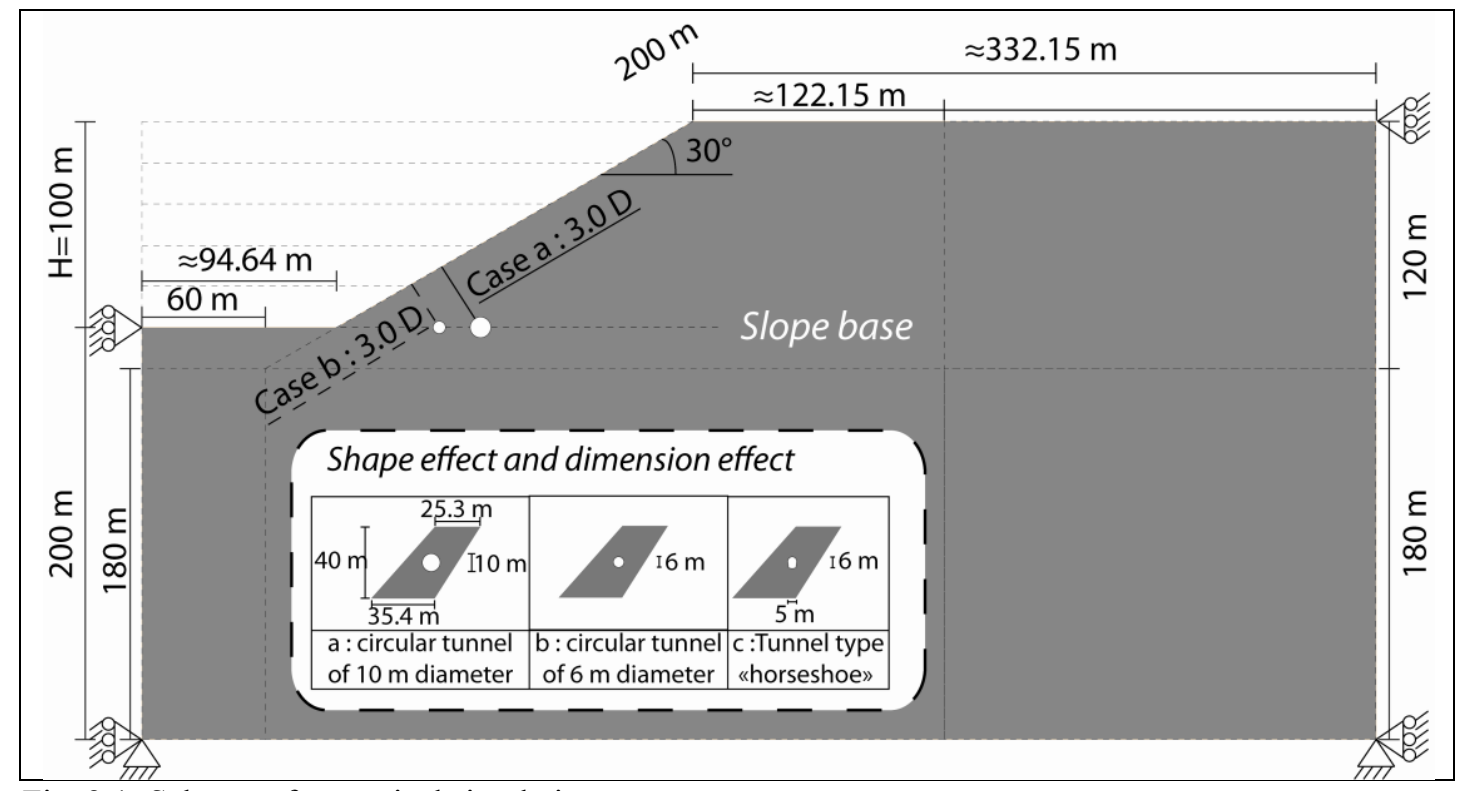

Fig. 2.1: Scheme of numerical simulations.

The model slope was assumed to be composed by one homogenous layer in dry condition to interpret clearly the only effect of tunnel's excavation on the slope's destabilization.

Elasticity and Mohr-Coulomb's failure criterion were used as the constitutive model for the ground. The ground properties are chosen to induce a stable slope with a low safety factor. Table 2.1 resumes the ground properties.

\begin{tabular}{ccccccccc}
\hline & $\begin{array}{c}\text { density } \gamma \\
\left(\mathrm{kN} / \mathrm{m}^{3}\right)\end{array}$ & $\begin{array}{c}\text { Cohesion } \\
\mathrm{c}(\mathrm{kPa})\end{array}$ & $\begin{array}{c}\text { Internal } \\
\text { friction } \\
\text { angle } \varphi \\
(\mathrm{deg})\end{array}$ & $\begin{array}{c}\text { Poisson } \\
\text { ratio } \\
v\end{array}$ & $\begin{array}{c}\text { Modulus of } \\
\text { deformation } \\
\mathrm{E}(\mathrm{MPa})\end{array}$ & $\begin{array}{c}\text { Shear } \\
\text { modulus } \\
\mathrm{G}(\mathrm{MPa})\end{array}$ & $\begin{array}{c}\text { Bulk } \\
\text { modulus }(\mathrm{MPa})\end{array}$ & $\begin{array}{c}\text { Tensile } \\
\text { strength } \mathrm{t} \\
(\mathrm{kPa})\end{array}$ \\
\hline Massif & 19.62 & 20 & 30 & 0.3 & 50 & 19.23 & 41.67 & 20.0 \\
\hline
\end{tabular}

Table 2.1: Material mechanical properties.

After the slope excavation process, the excavation of the tunnel is done by taking into account the progressive deconfinement process surrounding the tunnel by the "convergence-confinement method" (Sulem et al. 1987).

\subsection{Study of the factors of influence}

First, the deconfinement rate induces by the tunnel excavation and waiting before tunnel lining implementation vary according to the construction method. In theory, in a homogenous isotropic and elastic massif the deconfinement rate of the tunnel face is approximately of $50 \%$. To highlight the deconfinement rate influence, a circular tunnel of 10 meters of diameter was chosen to let us vary the deconfinement rate before tunnel lining implementation. The characteristics of the liner are presented in the Table 2.2. 


\begin{tabular}{ccccc}
\hline $\begin{array}{c}\text { Elastic modulus } \\
\mathrm{E}(\mathrm{MPa})\end{array}$ & $\begin{array}{c}\text { Inertia moment } \\
\left.\mathrm{I}^{4}\right)\end{array}$ & $\begin{array}{c}\text { Section area } \\
\left(\mathrm{m}^{2}\right)\end{array}$ & $\begin{array}{c}\text { Thickness } \\
(\mathrm{m})\end{array}$ & $\begin{array}{c}\text { Poisson ratio } \\
v\end{array}$ \\
\hline $44.8 \mathrm{E}^{3}$ & $1.8583 \mathrm{E}^{-2}$ & 0.7 & 0.7 & 0.2 \\
\hline
\end{tabular}

Table 2.2: Mechanical properties of the lining structure.

Second, the influence of the size of the tunnel on the slope destabilization is revealed when comparing at first the previous tunnel of 10 meters of diameter at a distance of 1.5 diameters of the slope surface with a small one of 6 meters of diameter at the same position (3D) in the slope. Next the influence of the size is studied when comparing a tunnel of 10 meters of diameter at a distance of 3 diameters with a tunnel of 6 meters of diameter at a distance of 3 small tunnel diameters.

Third, the influence of the tunnel shape on the slope destabilization and on stress-strain of the tunnel structure is studied when comparing the last circular tunnel of 6 meters of diameter at a distance of 3 small tunnel diameters with another one at the same position with a shape of horseshoe. The depth as well as the shape of the tunnel section influence strongly the evolution of the wall convergence around the structure (Gonzalez-Nicieza et al. 2008). The increase of the depth increases the rate of convergence. Moreover, the transition form of a circular section to a horseshoe section causes an asymmetry of the convergence around the tunnel associated with an anisotropic distribution of the stress state. For an asymmetric section, the convergence of the cross-section wall is maximal to the stronger radius of curvature of the structure; conversely it's minimal to a strong change of radius curvature of tunnel. In this case study, in addition to the tunnel shape, the stress state around the tunnel and the movement within the slope influence the asymmetry of convergence on the cross-section of the tunnel.

\section{Preliminary results}

\subsection{Influence of the deconfinement rate}

In the context of the destabilization level of the slope, the increase of deconfinement before the implementation of the liner causes an increase of shear deformations accompanied by a stress state relaxation deeper in the slope in the case of hard deconfinement. In other words, the increase of deconfinement leads to a stronger destabilization of the slope.

Around the tunnel structure, the tunnel structure displacement in the slope come along with deformations of his different constitutive elements as well as the convergence walls before the structure set up.

The increase of deconfinement before the implementation of the structure causes a reduction of stress (axial forces, shear forces and moments), as well as a more progressive evolution of stress around the structure. Moreover, the deconfinement advance induces a reduction of strain on the different structure elements but also a more significant convergence (Fig 3.1). All these observations are in agreement with the convergence-confinement method.

However, although the fact that the tunnel structure is circular, the distribution of stress and strain around the structure is anisotropic (Gonzalez-Nicieza et al. 2008). This anisotropic distribution of stress and strain state results from the context of shallow tunnel in a slope unlike the context method of tunnel in deep and isotropic stress state. The maximal strain and axial force of the structural elements are localized at the shoe of the right sidewall and at the left spring line.

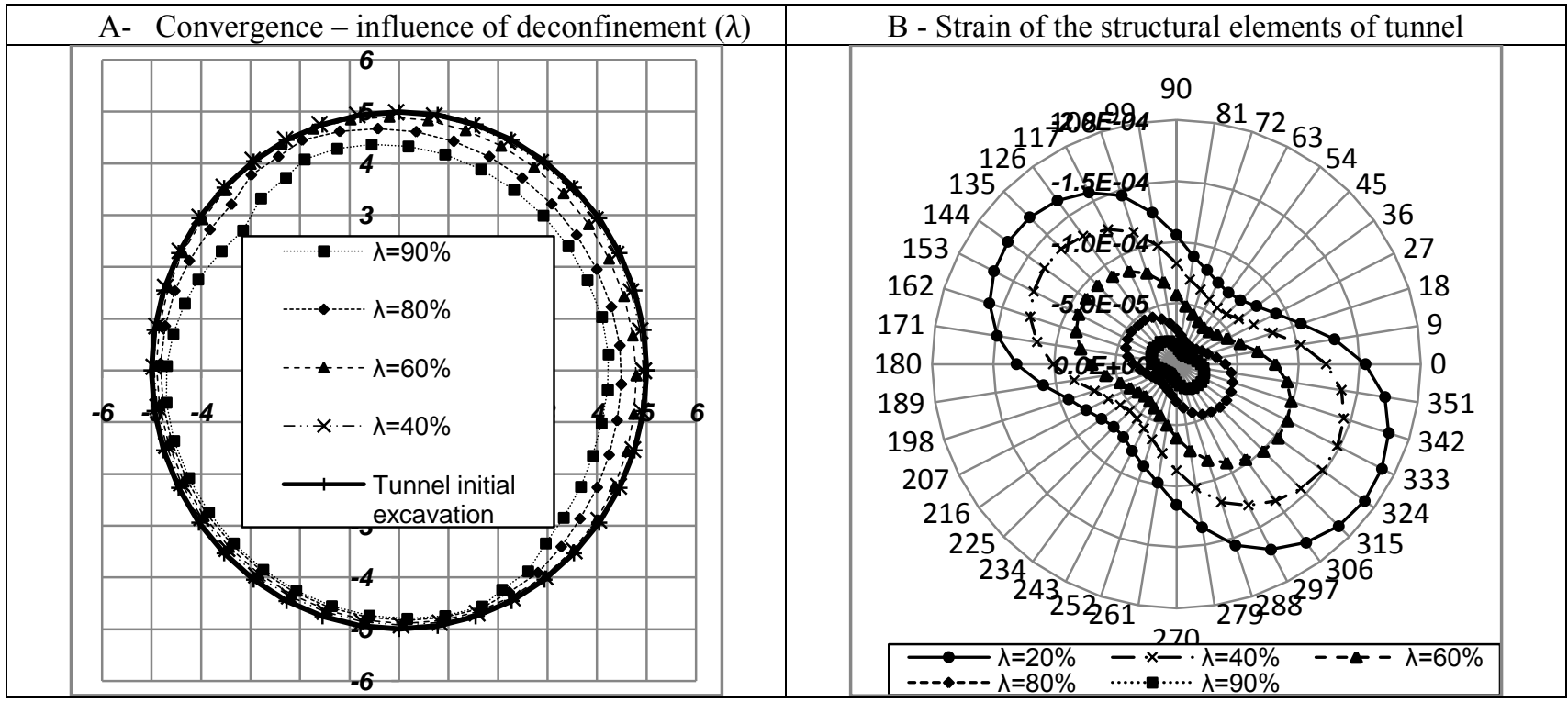

Fig. 3.1: Convergence and strain around the tunnel - influence of deconfinement $(\lambda)$. 


\subsection{Influence of the tunnel size}

In the context of the destabilization level of the slope, the set up of tunnel of small dimension and for a same position of the tunnel in the slope reduces the shear deformations and the destabilization of the slope. However for a same relative position (Fig. 2.1 case a versus case b), a tunnel of small dimensions (case b) results in a much more destabilization of the slope. In conclusion, the position of the tunnel in the slope is more significant for the destabilization degree of the slope.

Around the tunnel structure, the reduction of size, for a same localization of the tunnel in the slope (Fig. 2.1 case b), results in a reduction of convergence rate (Fig. 3.2). For this simile case, the translation vector of average convergence around the excavation is in the same direction. However, for a same relative position (Fig. 2.1 case a versus case b), a tunnel of small dimensions (case b) provokes also a reduction of convergence. But the translation vector of an average convergence does not exhibit the same direction.

Relating to the strain and stress of the tunnel structure elements, the reduction of the dimensions of the circular tunnel results in a reduction of stress and strain of the different elements constituting the structure (Fig. 3.2). The effect of tunnel size on stress and strain distribution in the structure implies that for a same position (Fig. 2.1 case b) that evolution on the cross-section remains similar. This similarity of distribution results of the same state of stress in the massif.

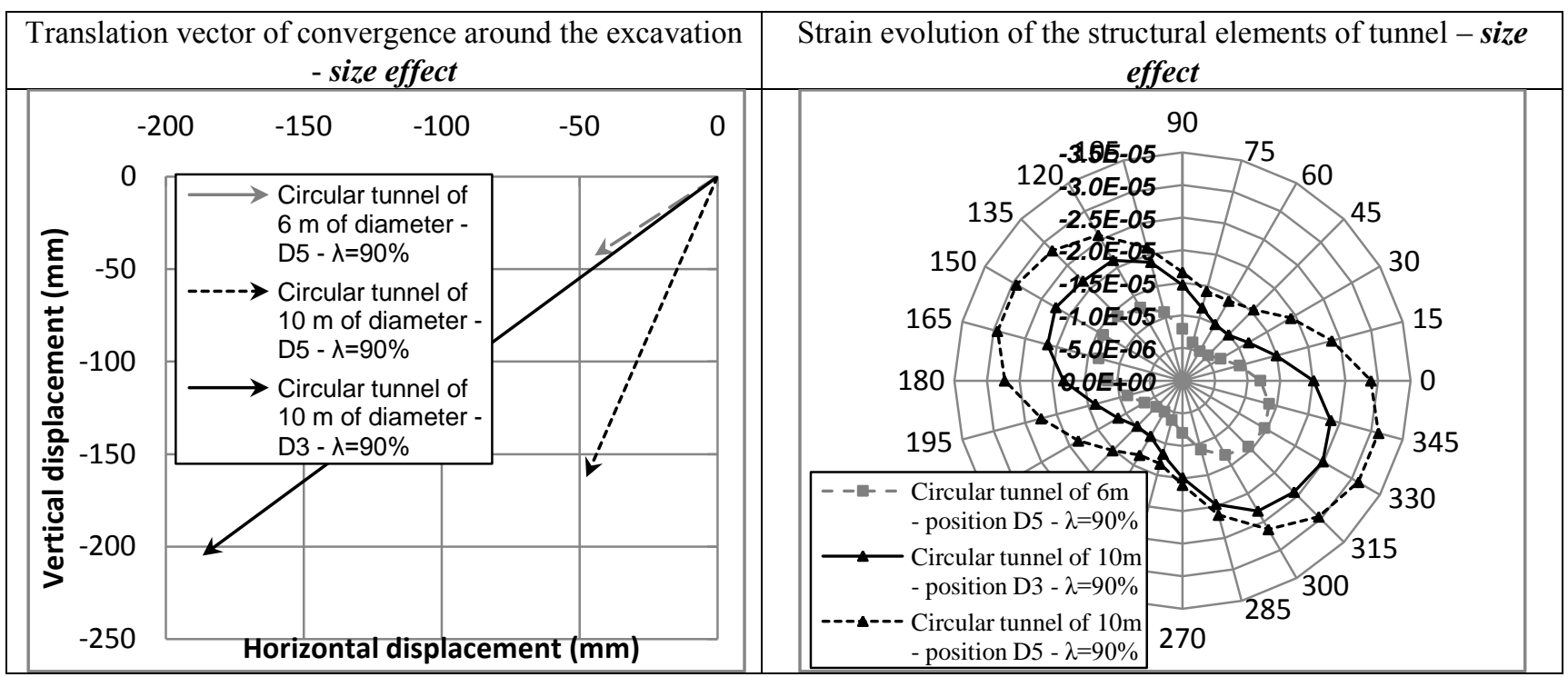

Fig. 3.2: Convergence and strain around the tunnel - influence of size.

In conclusion, studies of the influence of tunnel size must be considered for a same position in the slope corresponding to a same stress state around the structure. In the context, the reduction of the tunnel size results in a decrease of convergence, of the displacement of the structure of stress and strain in the structure.

\subsection{Influence of the tunnel shape}

The influence of the tunnel shape on the destabilization of the slope is smaller in relation to the size effect of the influence of deconfinement. For a same position in the slope and the same equivalent dimensions, the circular tunnel has a stronger negative impact for the slope destabilization.

Around the tunnel structure, the horseshoe cross-section results in an asymmetric convergence of walls not only due to the particular shape of the excavation but also to the context of slope near the tunnel. The maximum convergence due to the slope context is localizing near the spring line of the right sidewall. The minimum convergence is situated at the right side wall shoe also due to the slope context. The horseshoe shape slightly increases the convergence on the right sidewall and at the left sidewall shoe but decreases at the right sidewall shoe. The horseshoe section results in a slightly reduction of the convergence translation vector associated with a direction more vertically.

The convergence rate (Fig. 3.3), between the horseshoe shape and the circular shape is similar except near the right sidewall $\left(300<\theta<360^{\circ}\right.$ and $\left.0<\theta<60^{\circ}\right)$ and the shoe of the left sidewall $\left(180<\theta<225^{\circ}\right)$. The modification of the convergence distribution does not correspond exactly to the variation of the spatial distribution of convergence associated with the change of shape (Gonzalez-Nicieza et al., 2008). This difference must result of the situation of the tunnel near the slope associated with a dissymmetric stress state. 
Relating to the strain and stress of the tunnel structure elements, the tunnel shape effect is significant near the toe of the right sidewall (Fig. 3.3). At the right sidewall toe, the horseshoe shape provokes a high reduction of strain and axial forces. In contrast, this situation on the horseshoe cross-section is affected by a high angular variation of values of shear forces and moments accompanied by their inversion of sign.

The study of the effect of voids behind the tunnel structure on the stress distribution in the lining permits to demonstrate that the inversion of sign of the bending moment near the invert provokes the development of cracks if the tensile strength of the lining is not exceeded (Meguid and Dang. 2009).

The pathologies on the horseshoe cross-section structure near the toe of the right sidewall must be due to the shear forces and moments evolutions.

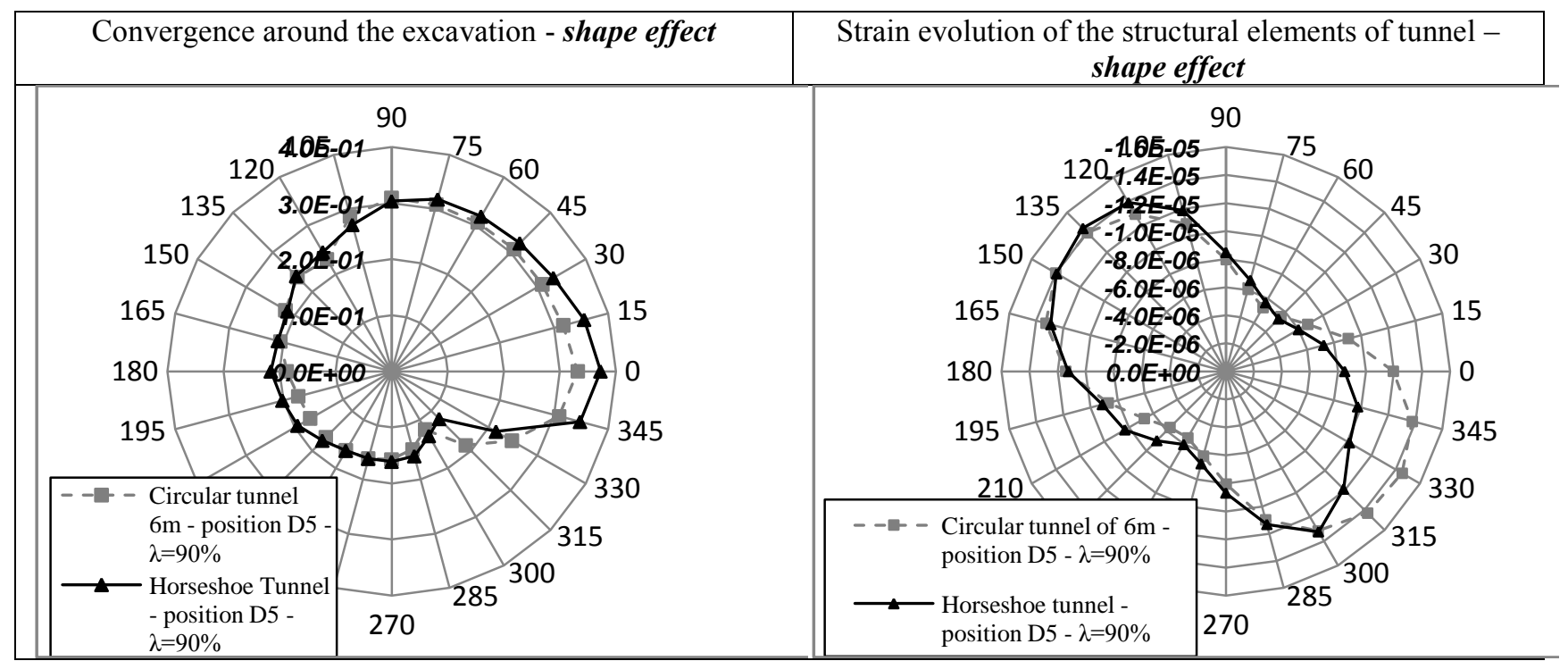

Fig. 3.3: Convergence and strain around the tunnel - influence of shape.

In conclusion, studies of the influence of tunnel shape must be considered for a combination of stress state and strain in the structure and convergence around the excavation. The evolution of the destabilization of the slope is not significantly affected by the shape of the tunnel effect.

\subsection{Tunnel construction impact on shear strain of tunnel surrounding ground.}

Anomalies on a tunnel structure are associated with the shear deformation of the surrounding ground. They were caused by the instability of the neighbouring slope corresponding to a variation of the ambient stress (Usman M., Galler R., 2013). After tunnel construction, a subsequent deformation, which increases the lining stress, is inherently a result of the variation in the ambient stresses. When a slope moves, its shear deformations in surrounding the ground increase (Wang T.T., 2010).

For all these parametric studies, maximum shear deformations in the surrounding ground are localized on the spring line of the downhill side $\left(\theta \approx 135^{\circ}\right)$ and on the sidewall base of the downhill side $\left(\theta \approx 300^{\circ}-315^{\circ}\right)$. However, the range of the shear deformations varies in all cases.

When the deconfinement before the lining set-up increases, the shear slip surface grows.

For a similar tunnel position in the slope, the reduction of the tunnel size causes a high reduction of the slope destabilization. The tunnel shape does not affect the shear slip surface significantly. A horseshoe shape tends to localize the maximum shear strain at the bottom of the sidewall and slightly increase the shear surface (Fig. 3.4).

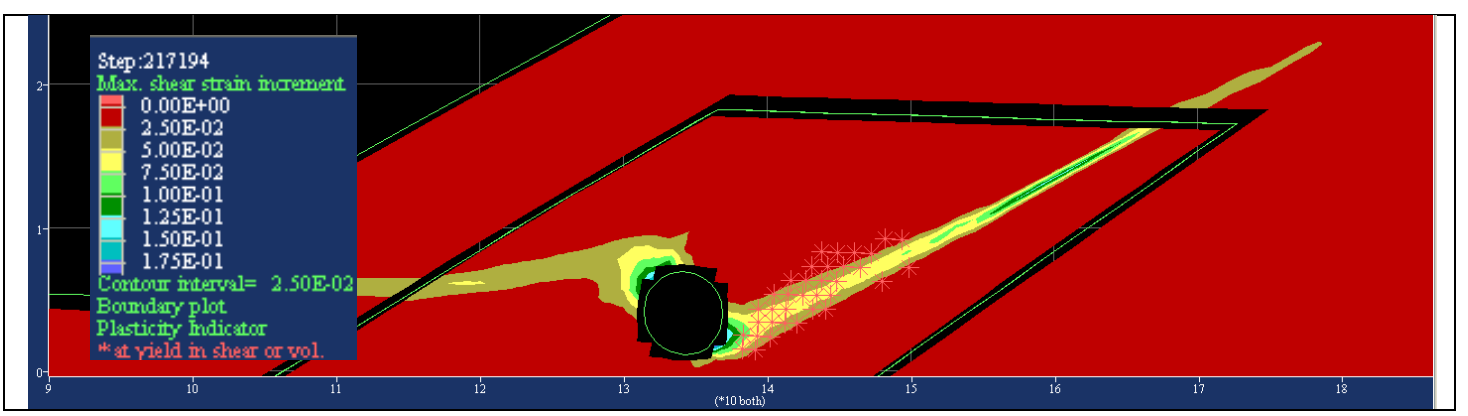




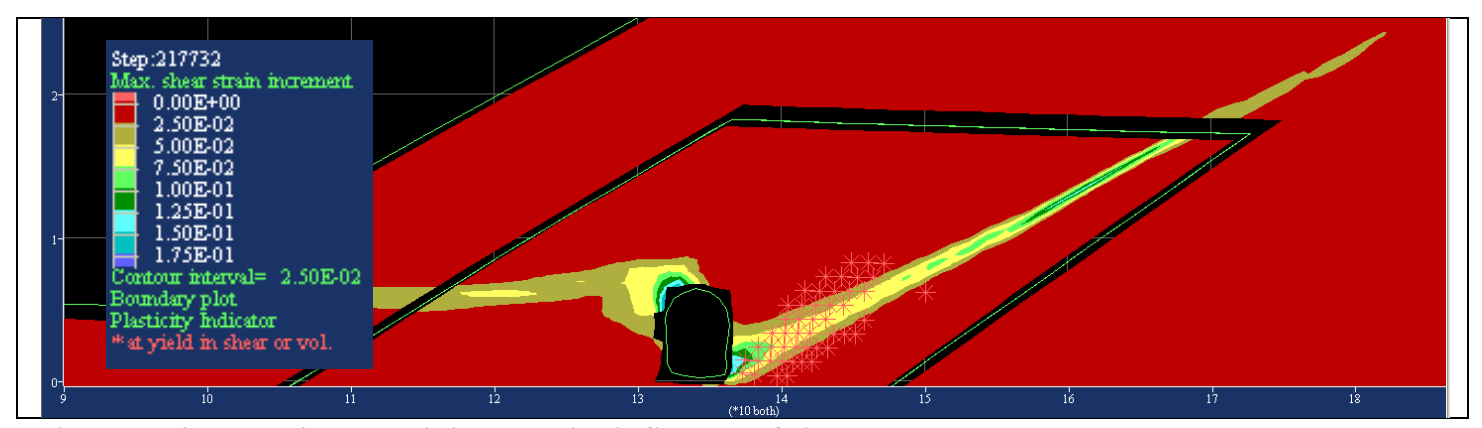

Fig. 3.4: Shear strain around the tunnel - influence of shape.

\section{Conclusion}

The structural behavior of a tunnel liner was investigated numerically in the context of interaction with slope instability. These parametric studies conducted are related to the construction techniques influence. Precisely the relative influence of the deconfinement's level when setting out the lining, the morphology of the transverse section of the tunnel, its dimensions of the lining structure are studied through several parametric steps. The following conclusions are drawn from the results and summarized below:

(1) The evolution of deconfinement $(\boldsymbol{\lambda})$ resulting from the tunnel excavation is in agreement with the convergenceconfinement method, that is to say: the reduction of stress and strain in the liner associated with the increase of the convergence and of the deconfinement. However, the tunnel situation in the base of slope results in a dissymmetric stress state accompanied by a heterogeneous distribution of stress and strain in the lining.

(2) The reduction of the tunnel size must be studied for a similar localization in the slope corresponding to a similar stress state around the structure. The decrease of the tunnel size results in a reduction of stress state and strain in the tunnel lining. Furthermore, the evolution of the values of stress is more progressive for a tunnel of small size.

(3) For a horseshoe section, the stress state, the strain in the lining and the convergence evolves with the specific shape. The toe of the right sidewall (massif side) of the horseshoe shape is the location subject at the high variations compared with the circular cross-section shape. For the horseshoe cross-section this position is characterized by less strain of lining elements, but a high angular variation of values of shear forces and moments accompanied by their inversion of sign.

It should be noted that the above conclusions are based on a simplified 2D analysis whereas the tunnel excavation process is affected by 3D problems near the tunnel font advance. The reported results are applicable to cases where the examined tunnels are constructed in soft and homogeneous ground represented by the Mohr-Coulomb material model. In addition, the physical process of deconfinement is not linear. Other main construction techniques play a role, such as velocity of excavation that must be taken into account. Nevertheless this last factor of influence implies a constitutive law taking time into account.

\section{References}

- Wang T.T., 2010. Characterizing crack patterns on tunnel linings associated with shear deformation induced by instability of neighboring slopes. Engineering geology 115. Pages 80-95.

- Leung C., Meguid M.A, 2011. An experimental study of the effect of local contact loss on the earth pressure distribution on existing tunnels linings. Tunneling and underground space technology 26. Pages 139-145.

- Meguid M.A., Dang H.K., 2009. The effect of erosion voids on existing tunnels linings. Tunnelling and Underground Space Technology 24, 278-286.

- Usman M., Galler R., 2013. Long term deterioration of lining in tunnels. International Journal of Rock Mechanics \& Mining sciences 64. 84-89.

- Ashtiani M. \& Palassi M., Ahmadi A., 2010. Effect of excavation of tunnels in the convex slopes using distinct element method. Rock mechanics in civil and environmental engineering. Pages 391-394.

- Sulem, J., Guenot A., Panet M., 1987. An analytical solution for time-dependent displacements in a circular tunnel. International journal of rock mechanics and mining sciences \& geomechanics abstracts 24, pp. 155 - 164 .

- Gonzalez-Nicieza C., Alvarez-Virgil A.E., Gonzalez-Palacio C.,Menendez-Diaz A., 2008. Influence of the depth and shape of a tunnel in the application of the convergence-confinement method. Tunneling and underground space technology 23. Pages 25-37.

- Koizumi Y., Date K., Lee J., Fujisawa K., Yokota Y. \& Yamamoto T., 2010. Numerical analysis of landslide behavior induced by tunnel excavation. Rock mechanics in civil and environmental engineering. Pages 555-558. 